\title{
The Importance of Expanded Forehead Flap in Nasal Reconstruction
}

\author{
KARIMA T. ISMAIL, M.D.; MARIAM T. ISMAIL, M.D. and AHMED T. ISMAIL, M.D. \\ The Department of Plastic and Reconstructive Surgery, Faculty of Medicine, Cairo University
}

\begin{abstract}
Introduction: Nasal reconstruction is a difficult problem because it entails reconstruction of skin, cartilage, osseous frame work and lining mucous membrane [1]. The result must be satisfactory both cosmetically and functionally [2].

The anatomical reconstruction depends on the principle of subunit divisions of the nose. Which states: If the reconstruction is less than the defective subunit the result will appear patchy. On the other hand, if the reconstruction exceeds the limits of the subunit the nose will appear unnatural $[3,4]$.

Local and regional flaps are used in nasal reconstruction each type has its own advantages, disadvantages and donor site morbidity [5-9]. The aim of this work is to demonstrate the advantages and disadvantages of expanded forehead flap in nasal reconstruction.
\end{abstract}

Material and Methods: A retrospective review of 25 consecutive cases of total or nasal dorsum reconstruction who were operated upon in a single clinic by 3 separate surgeons adopting the same principle of expanded forehead flap, between January 2010 and January 2017.

In this technique the median forehead skin is expanded with a 200-ml envelope for 6-8 weeks, and then a forehead flap is incised to match the nasal defect [10].

Results: Surgical follow-up varied from a minimum of 6 months to a maximum of 2 years with average follow-up of 1 year. Among a total of 25 patients, 23 patients (92\%) complied with follow-up, and $21(91 \%)$ of these patients were satisfied. One case only complicated and the expander extruded and had to be removed.

Conclusion: The tint of forehead skin is similar to nasal skin. Forehead flap is well vascularized and is lying adjacent to the nose. Forehead is a multilaminar structure which allow the usage of skin grafts as inner lining and because of its high vascularity all types of structural support can be used. Expanded forehead flap provides large, excess forehead skin and primary closure of donor site is applicable. During the process of expansion, the skin is thinned out so do not need de-fattening and re-contracture do not occur. Therefore, forehead flap is always a good reconstructive option in large nasal defects.

Key Words: Forehead - Flap - Nasal reconstruction.

\section{INTRODUCTION}

The nose is the most prominent feature on the human face, critically involved in appearance, both to oneself and to others, and it is involved significantly in the perception of beauty, both publicly and privately [11]. Because of its central location on the face, plane of projection, and relatively weak chondro-cutaneous support structure, the nose is susceptible to injury, and deformities are readily apparent. Nasal reconstruction is a difficult problem because it entails reconstruction of skin, cartilage, osseous frame work and lining mucous membrane [1]. The result must be satisfactory both cosmetically and functionally [2]. There are principals for nasal reconstruction:

1- There is an inherent desire in human beings to look normal, not even different.

2- Our eyes see the unexpected and disregard what looks like normal.

3- The normal is recreated by establishment of fascial contours.

4- The number or presence of scars is of lesser importance.

5- Flaps are designed to replace topographic units, not defects; such designs lend camouflage to the final result.

6- Exact patterns are used to design flaps.

7- The contralateral normal used as a guide.

8- Scars are always placed in wrinkle or contour lines.

9- Like tissue are replaced with like tissue in 3$\mathrm{D}$ designs.

10- Donor sites chosen and treated aesthetically.

11- Forehead flap is always a good reconstructive option in large nasal defects [5-9]. 


\section{Forehead flap:}

The tint of forehead skin so exactly matches that of the face and nose that it must be first choice. Is not the forehead the crowning feature of the face and important in expression? Why then should we jeopardize its beauty to make a nose? First, because in many instances, the forehead makes far and away the best nose. Second, with some plastic juggling, the forehead defect can be camouflaged effectively" [12].

In instances where the nasal septum is not available as a source for lining flaps or can provide lining only to the caudal aspect of the nose, a paramedian flap may save as a source for lining. The flap is raised in a fashion similar to that used for covering flaps. The frontalis muscle and galea are removed, and the flap is thinned of its subcutaneous tissue. The flap is then folded on itself and delivered of the nasal passage by tunneling it under the glabellar skin to reach the lining defect. The flap is suspended to framework grafts of bone and cartilage. A second paramedian forehead flap is then used as a cover flap for the exterior of the nose. In cases where the upper nasal vault is intact, the lining flap may be delivered to the middle vault through the lateral aspect of the middle vault defect. In this case, to accommodate the flap, the necessary framework in the area of the fenestrum is delivered until the flap is detached. The forehead flap used for lining is detached from the brow after 3 weeks. Detachment of the external flap is delayed an additional 3 to 6 weeks to maximize revascularization of the framework grafts [13].

There are different types of forehead flap; the Median forehead flap is used to reconstruct larger defects of the nasal dorsum, sidewall, and tip. The flap receives its blood supply from the supratrochlear artery on one or both sides and width of flap should not exceed $3-3.5 \mathrm{~cm}$ to allow primarily closure of donor defect. Additional length on the midline forehead flap is achieved by one of two variations: (1) Tilting the axis of the flap to a more oblique position or (2) Lowering the point of rotation by back-cutting the pedicle in the glabella. As in all operations meticulous hemostasis is required.

The flap takes from 6 month to 1 year to heal completely. If it is too thick or if unsightly scars have formed, the flap may be thinned (defatted) and/or the scars revised by means of small Zplasties or W-plasties. The Paramedian forehead flap is a variation of median forehead flap; in which the blood supply is based on one supratro- chlear vessel and the flap axis is tilted in an oblique manner [14]. Another variation is the Gillies-Millard "Sea gull-wing "design of a midline forehead flap and the donor defect is closed primarily [12].

\section{Median forehead flap with soft-tissue expansion:}

With the recent development of skin expansion techniques, there is the intriguing possibility of transferring initially expanded skin for nasal reconstruction and being able to close the donor defect primarily. Certainly, this would make the forehead defect less disfiguring, although the expanded skin is stiff and indelicate when the underlying capsule is left attached.

In this technique the median forehead skin is expanded with a 200-ml envelope for 6-8 weeks, and then a forehead flap is incised to match the nasal defect [10].

Broad median forehead flap following preliminary soft-tissue expansion with an expander. A small incision in the scalp gives access for inflating the envelope. The flap is dissected from the galea and periosteum in a subcutaneous plane, preserving the frontalis muscle (oblique forehead flap). Better results without a rigid scar we can get with lateral expansion.

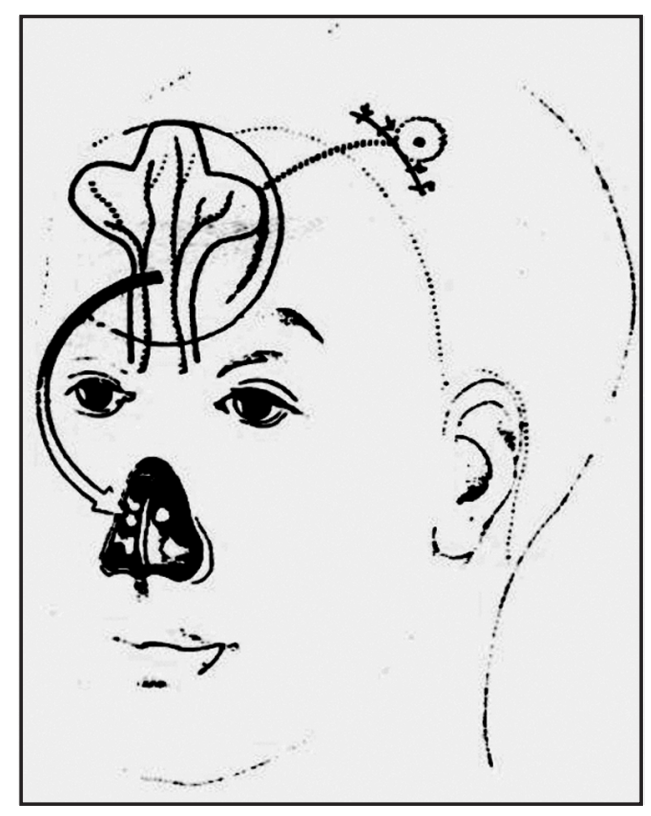

Fig. (1): Expanded Forehead flap.

Potential problems with skin expansion include the following: (1) Removal of the capsule at the time of transfer may jeopardize the vascular supply to the transferred skin; (2) Lamination of the flap with a lining composite graft, if needed, is difficult 
to control with an expander beneath; and (3) The extent of late retraction of expanded skin is not yet clear. Since nasal dimensions are critical, even slight late contraction would distort the result.

The concept of skin expansion is attractive, put its ultimate place in nasal reconstruction is undetermined [15].

\section{Three staged forehead flaps:}

Stage 1: A full-thickness, multilamellar, nonexpanded forehead flap (skin, subcutaneous fat, and frontalis muscle) is elevated. The cover defect is replaced exactly, using a template derived from the contralateral normal side or from an ideal. It is inset, without tension or blanching, with a single layer of fine silk suture. If altering and enlarging the defect will improve the final aesthetic result, adjacent normal tissue within nasal subunits is excised, and the entire subunit is resurfaced, rather than only the defect $[3,16]$. Primary support cartilage grafts are a first choice, but they can be positioned in a delayed primary fashion at the second-stage intermediate operation.

The forehead donor site is closed in layers after undermining widely in the subgaleal plane. Any gap that cannot be approximated is allowed to heal secondarily.

Stage 2: Three weeks later, the full-thickness forehead flap, now well healed to the recipient bed is, in effect, physiologically delayed. In the intermediate operation, forehead skin with 3 to $4 \mathrm{~mm}$ of subcutaneous fat (nasal skin thickness) is easily elevated in the unscarred subcutaneous tissue plane over the entire nasal inset, except for the columella. This creates a maximally vascularized bipedicle flap that extends from the intact supratrochlear brow pedicle to the columella. The extent of flap elevation can vary, depending on the exposure required for softtissue excision and additional delayed primary cartilage grafting. Most often, it is complete except for the columellar inset. Perhaps because of the period of delay or the accommodation of the flap pedicle to the initial twist at transfer, its blood supply is excellent. In fact, forehead skin (without frontalis muscle) can be completely reelevated off the nose, maintaining no distal inset, without significant risk, if such exposure is needed to allow more complete subcutaneous excision or cartilage graft placement. Usually, the intermediate operation is performed under general anesthesia, avoiding the distortion created by local anesthesia or the chemical blanching of epinephrine. A combination of digital two-hand palpation and transillumination allows the elevation of a smooth, even, thin, supple, conforming skin cover of ideal quality. The skin retains excellent color and capillary refill. The slightly edematous and previously undissected subcutaneous plane separates easily from underlying tissues, with little bleeding from the deep surface of the skin flap. Axial subcutaneous vessels lying in the subdermal superficial fat under the skin become visible and are not injured. The underlying subcutaneous tissue, frontalis muscle, and previously positioned primary cartilage grafts are exposed. This excess soft tissue, conglomerate of cartilage, fat, and scar, heals into a rigid living structure that bleeds readily and is excised to carve an ideal subunit subsurface architecture. Previously positioned primary cartilage grafts are visible and can be remodeled by sculpting, further augmentation, or repositioning, if required. Delayed primary cartilage grafts can also be placed over vascularized lining skin grafts or the forehead skin that had been folded for lining. If the lining is deficient because of an initial design error or necrosis, additional skin grafts for the lining can be used to expand the available lining. After creation of an ideal subsurface architecture by soft-tissue excision and cartilage grafting, the forehead skin (now of nasal skin thickness) is replaced on the underlying rigid, recontoured three-dimensional recipient bed with quilting sutures to close the dead space and re-approximate the flap to the recipient site.

Stage 3: Three weeks later (6 weeks after transfer), the pedicle is transected. The inferior forehead scar is reopened, and the proximal pedicle is unfurled, trimmed, and inset as a small inverted $\mathrm{V}$ at the medial brow to simulate a frown crease. The distal flap is elevated with 3 to $4 \mathrm{~mm}$ of subcutaneous fat, and the proximal recipient bed inset is sculpted, as needed, by further excision of excess subcutaneous fat, frontalis muscle, and scar to define the dorsal lines, alar creases, and sidewall junction. The flap inset is completed over a stable, sculptured rigid platform flap whose nasal shape shows through the thin, conforming forehead skin $[16,17]$.

The planned three-stage forehead flap technique of nasal repair with an intermediate operation:

1- Allows the creation of a thin, supple, conforming cover from a thick forehead flap, with little risk of necrosis;

2- Uses primary and delayed primary grafts and permits modification of initial cartilage grafts to correct failures of design, malposition, or scar contracture before pedicle division;

3- Creates an ideal rigid subsurface framework of hard and soft tissue by cartilage grafting and 
subcutaneous excision, which is reflected through overlying skin and blends well into the adjacent recipient tissues before pedicle division;

4- Expands the applications of lining techniques to include the use of skin grafts for lining at the first stage, or as a "salvage" procedure during the second stage, and also permits the aesthetic use of a folded forehead flap for lining;

5- Shows that a skin graft or skin folded as an extension of a forehead flap integrates into adjacent normal lining and can be separated from the overlying cover from which it was initially vascularized, permitting delayed primary cartilage grafting;

6- Ensures maximal blood supply and vascular safety to all nasal layers;

7- Provides the surgeon with options to salvage reconstructive catastrophes;

8- Improves the aesthetic result while decreasing the number and difficulty of revision operations and overall time to repair; and

9- Provides insight into the nature of wound injury/repair in nasal reconstruction [18].

\section{PATIENTS AND METHODS}

A retrospective chart review was performed for all patients from January 2010 to January 2017 who underwent expanded forehead flap for total nasal construction. Fifteen patients were identified. Demographic data, comorbidities, smoking, operative duration, defect (cause, size, location) postoperative complications, revisions and long-term results were reviewed. Expanded forehead flap was offered to all patients with either total or near total nasal reconstruction. Smoking cessation was required; if applicable for 4 weeks preoperatively and for 3 weeks after procedure.

\section{Surgical technique:}

Under general anesthesia, unless there is a contraindication. 200cc oval tissue expander is placed in the forehead through vertical incision in the scalp in the sub-galleal plane and drain. The expander is expanded for 8 weeks, then the patient is ready for second stage. Second stage of procedure: Flap incision (according to measurements), expander removal, excision of the capsule, hemostasis, structural frame work reconstruction and inset of the flap. Third stage, separation of the flap.

\section{RESULTS}

Fifteen patients were identified who went expanded forehead flap from January 2010 to January
2017. Chart data were obtained for all patients. The average age of the study population was 47.5 years (range, 35 to 60 years).

\section{Operative findings:}

All cases were performed under general anesthesia. Except one case who was decompensated heart failure who was not suitable for general anesthesia and was operated under local anesthesia and sedation. Operative times of third stage ranged from 4 to 6 hours with an average of 5 hours. Operative time decreased over the years with increasing experience. The majority of the patients are discharged on day 1 postoperatively.

\section{Follow-up:}

Average follow-up duration was 3 years. The longest period of clinical monitoring for these patients was 5 years; the shortest duration was 6 months. Majority of the cases complied to followup [90 percent], majority of the followed-up cases [87percent] were satisfied.

\section{Complications:}

In the interest of precise documentation, all adverse events, were documented. Total complication rate was $13 \%$; varied from early to late complications. Early complication was 1 case of expander extrusion. Late complication 1 case of redness and hotness and flap separation.

\section{Cases:}

Case 1:

Female patient, 75 years old complaining of huge rodent ulcer.

Involved subunits: All subunits of the nose except root of the nose.

Procedure: Excision with safety margin $4 \mathrm{~mm}$ of all skin, sub cutaneous tissue and cartilaginous frame work of the nose.

Internal lining: Bilateral septo-perichondrial anteriorly based hinge flap from the remnants of the septum.

\section{Structural support:}

- Septal graft: L-shaped for frame work reconstruction.

- Conchal graft: For lower lateral, cartilage reconstruction.

External covering: Expanded forehead flap.

Patient satisfaction: Good. 


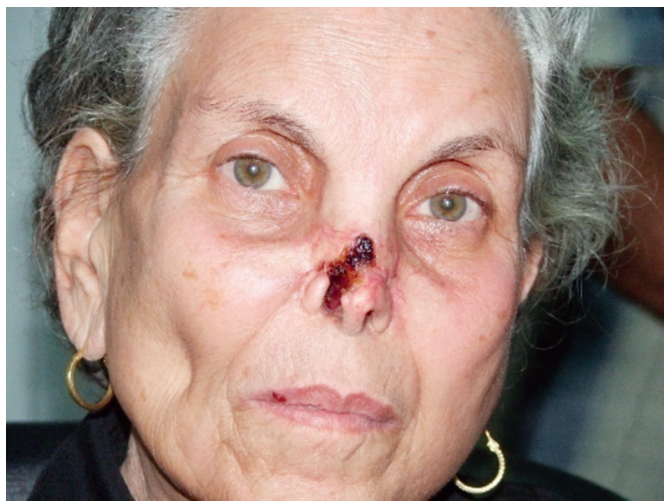

Fig. (2A): Pre-operative.

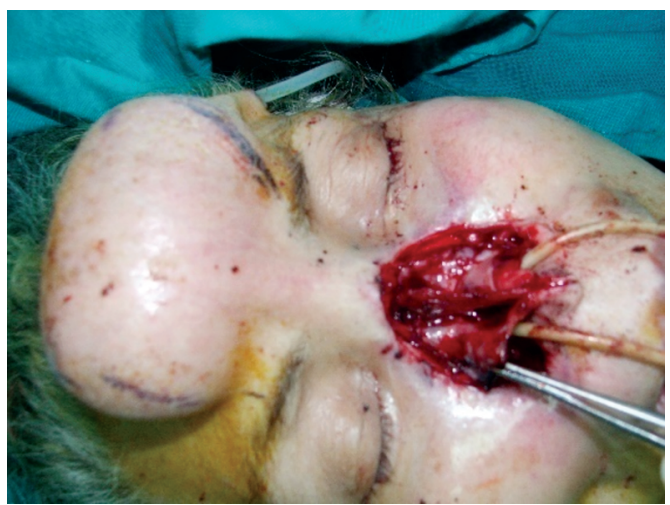

Fig. (2C): Intraoperative bilateral septo mucoperichondrial flap.

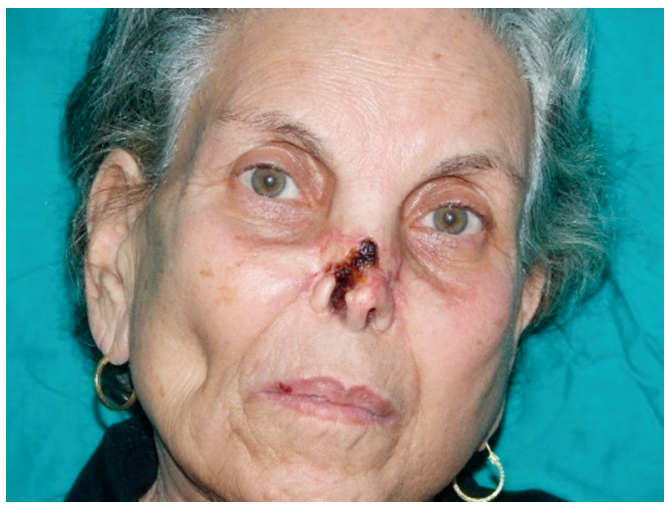

Fig. (2E): Pre-operative (front view).

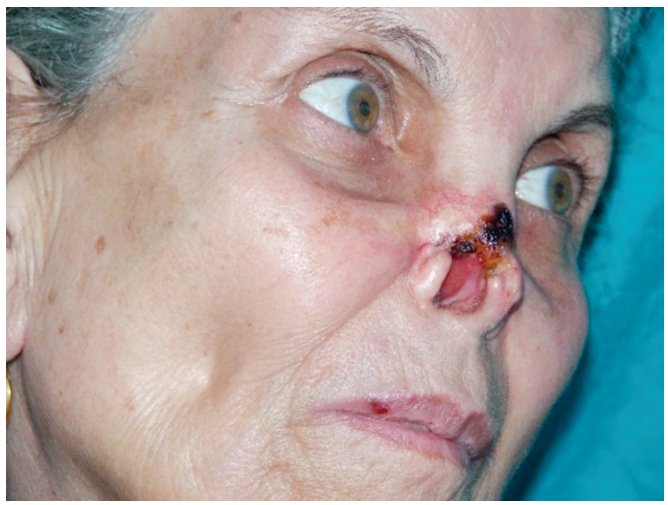

Fig. (2G): Pre-operative (lateral view).

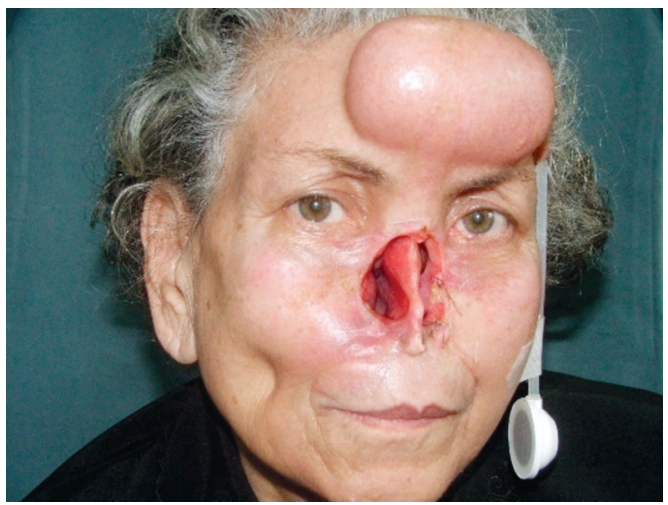

Fig. (2B): Post-operative after tissue expansion.

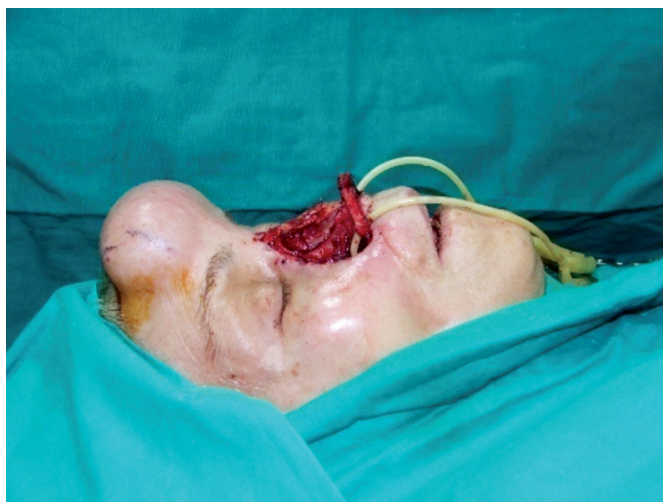

Fig. (2D): Intraoperative bilateral conchal graft.

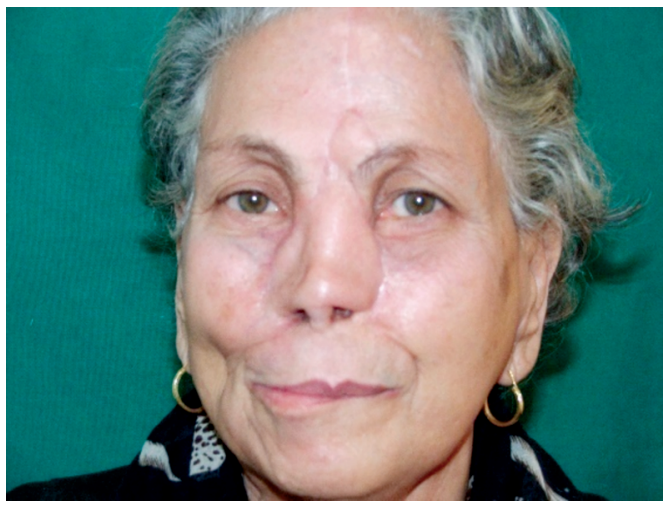

Fig. (2F): Post-operative (front view)

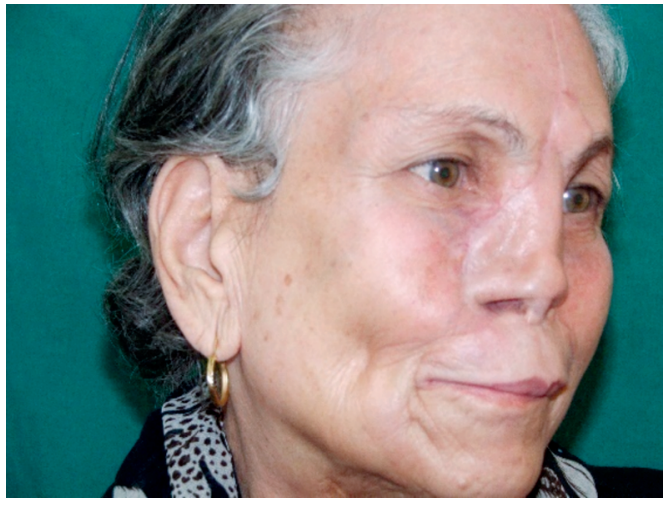

Fig. (2H): Post-operative (lateral view). 


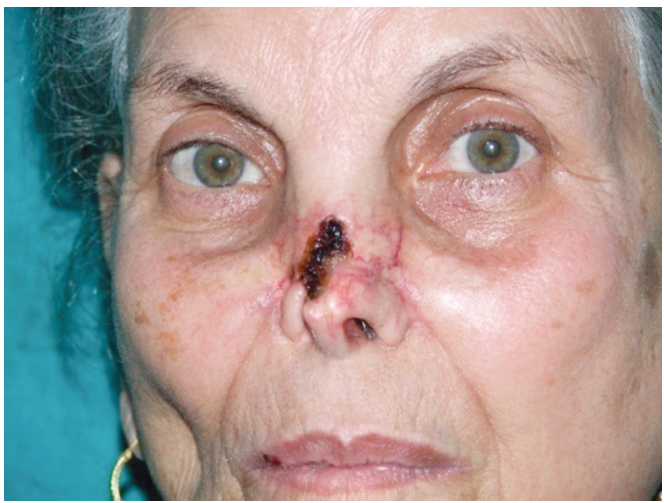

Fig. (2I): Pre-operative.

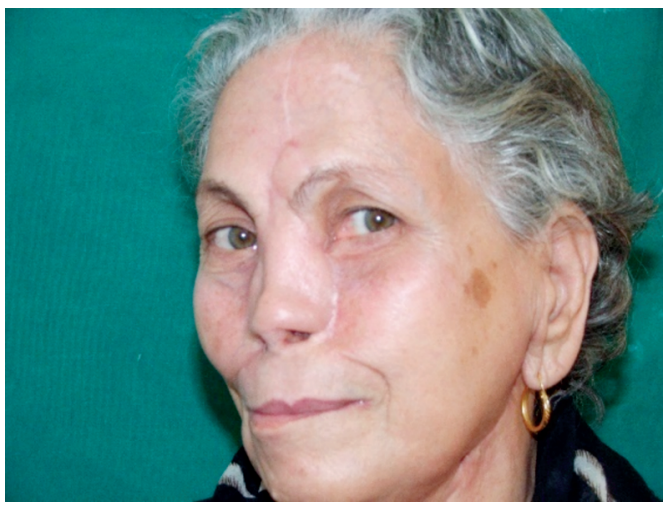

Fig. (2J): Post-operative.

Case 2:

Female patient, 19 years old complaining of contracted nose due to Neurofibromatosis excision and coverage by split thickness graft.

Involved subunits: All subunits of the nose.

Procedure:

1- Expander in forehead $50 \mathrm{ml}$, inflated up to $150 \mathrm{ml}$ through 3 months than 3 weeks interval between last injection and operation.

2- Removal of split thickness graft.

External covering: Expanded forehead flap.

Patient satisfaction: Excellent.

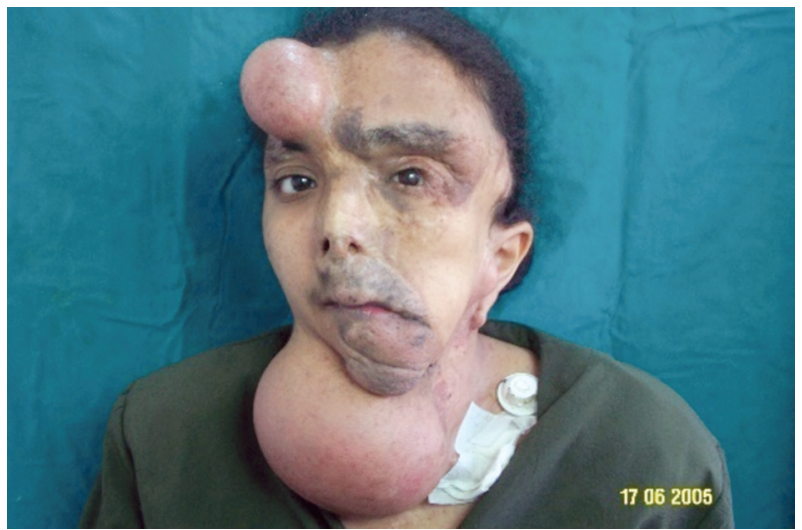

Fig. (3A): Pre-operative.

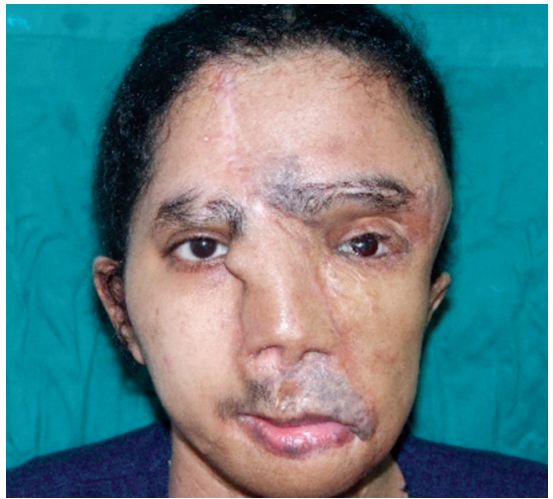

Fig. (3B): Post-operative before separation of the flap.

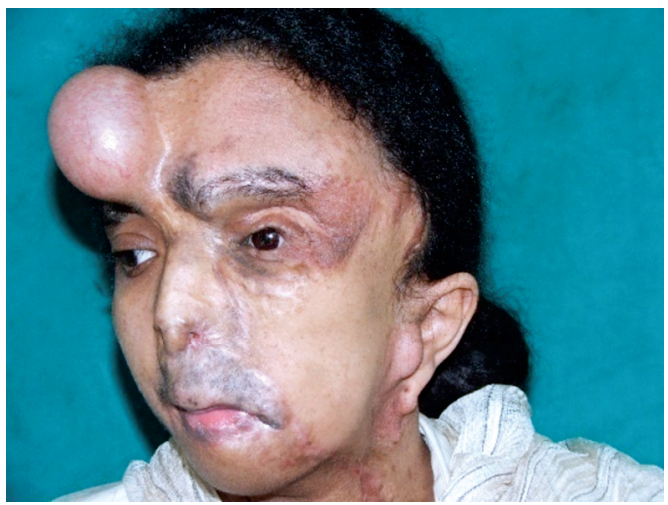

Fig. (3E): Pre-operative.

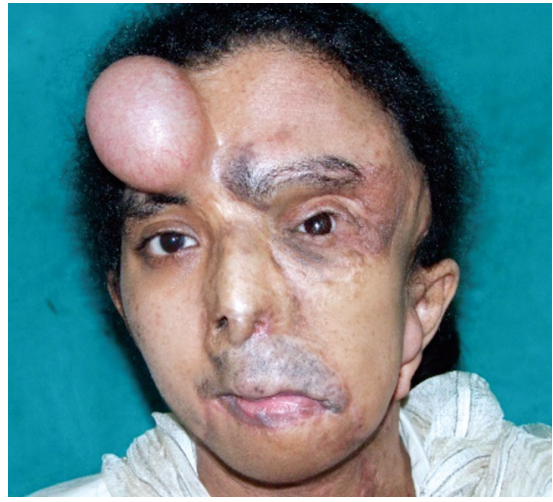

Fig. (3C): Pre-operative.

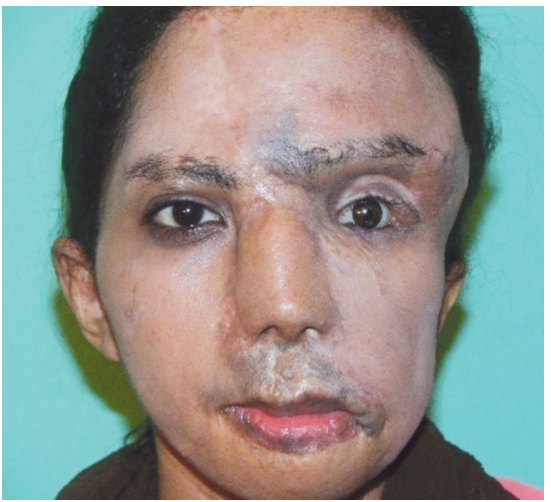

Fig. (3D): Post-operative.

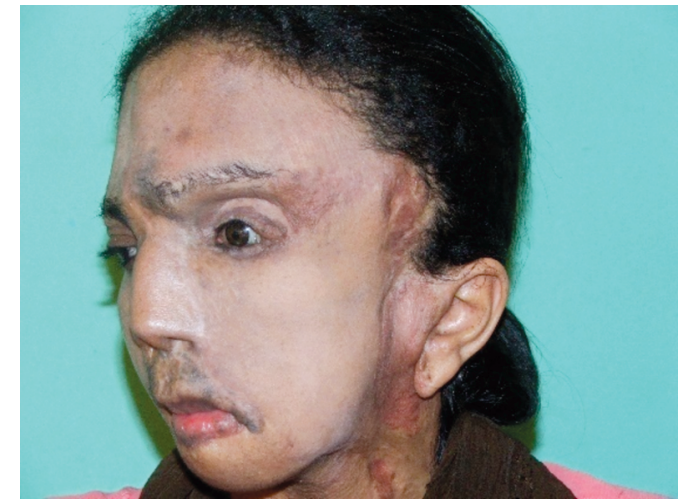

Fig. (3F): Post-operative. 
Case 3:

Male patient, 21 years old complaining of old gunshot to the face. cheek.

Involved subunits: Right nasal side wall, right

\section{Procedure:}

1- Expander in forehead $50 \mathrm{ml}$ continue as before.

2- Excision of the scar and determining size of the defect.

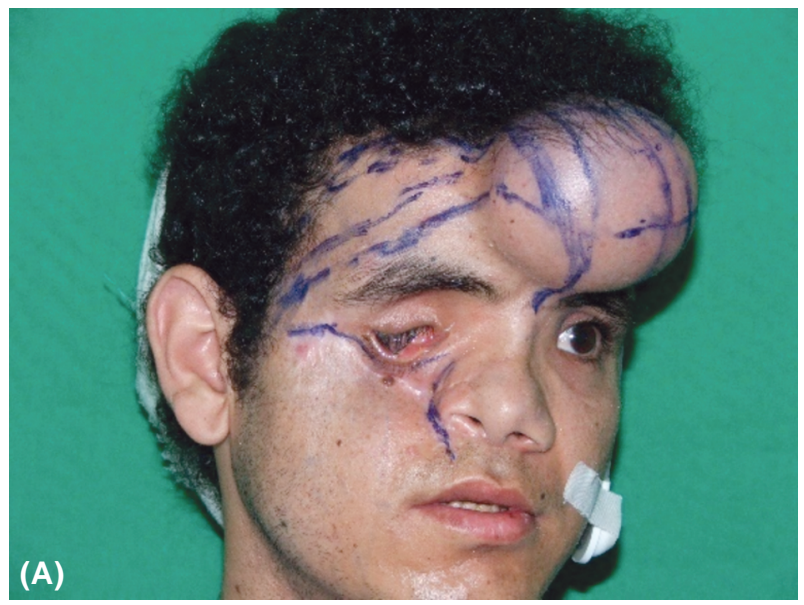

Fig. (4): (A) Pre-operative) lateral view). (B) Post-operative (lateral view).

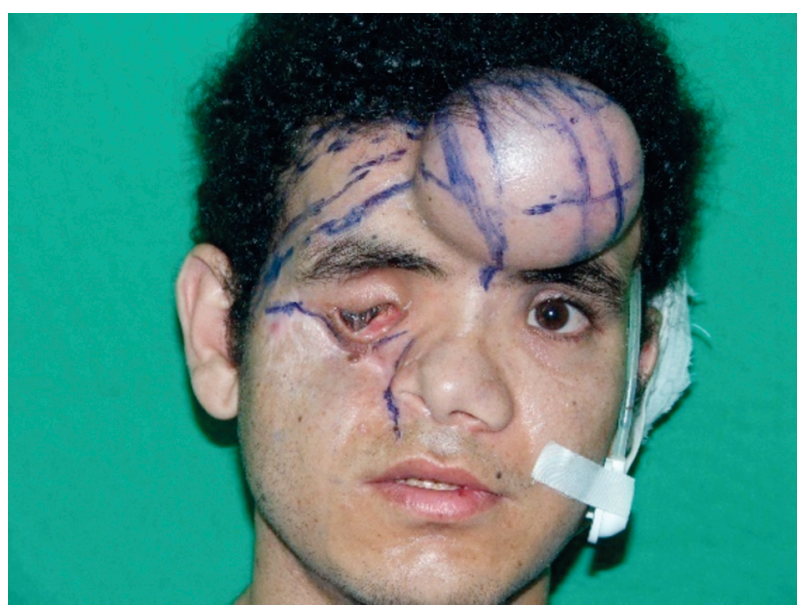

Fig. (4C): Pre-operative.

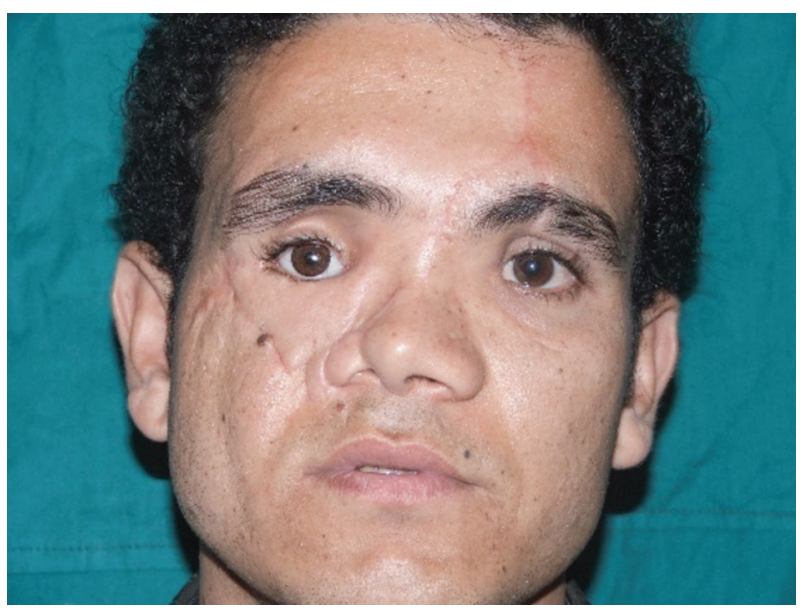

Fig. (4D): Post-operative.
Case 4:

Female patient, 18 years old complaining of congenital hypoplasia of the nose.

Involved subunits: Tip, columella, distal nasal dorsum.

Procedure: 1- Expander in the forehead 50ml (mentioned before).

Structural support:

- Conchal graft: For right upper lateral cartilage reconstruction.

- Septal graft: For columellar strut.

- Iliac bone graft: For maxillary reconstruction.

External covering: Expanded forehead flap.

Patient satisfaction: Good.

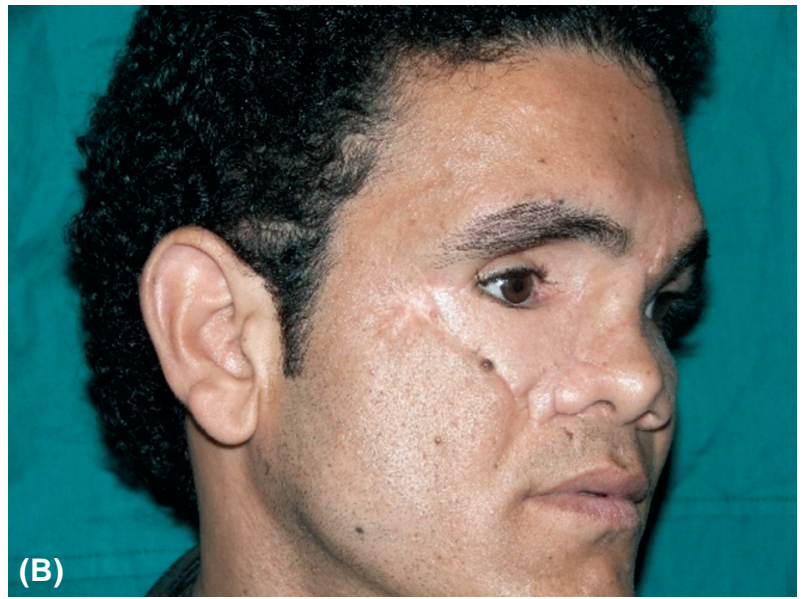

(B) 


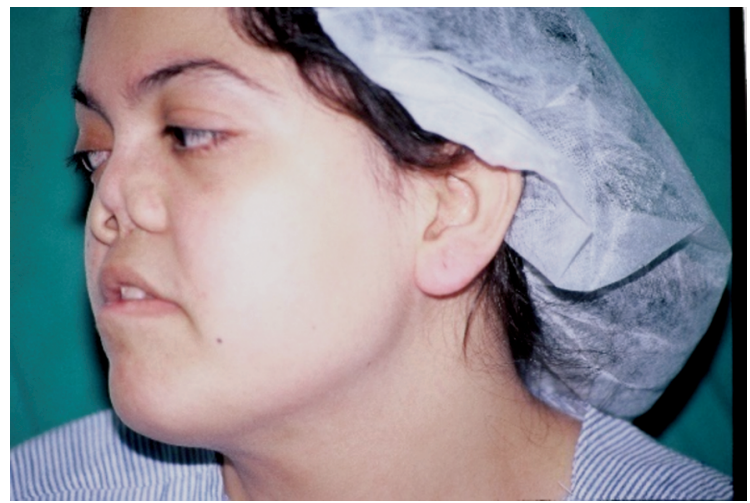

Fig. (5A): Pre-operative.

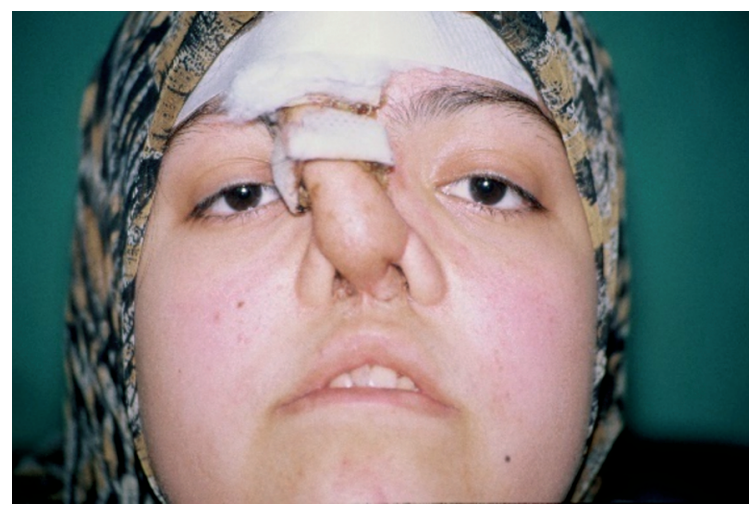

Fig. (5C): Pre-operative before separation of the flap.

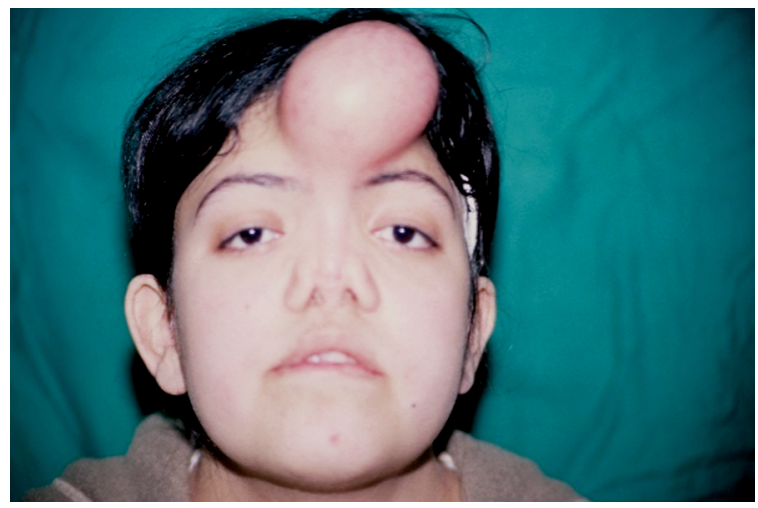

Fig. (5E): Pre-operative (front view).

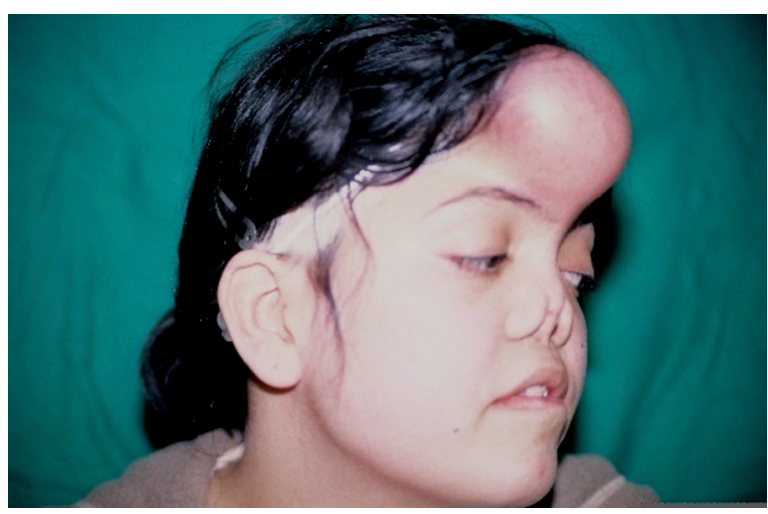

Fig. (5G): Preoperative (lateral view).

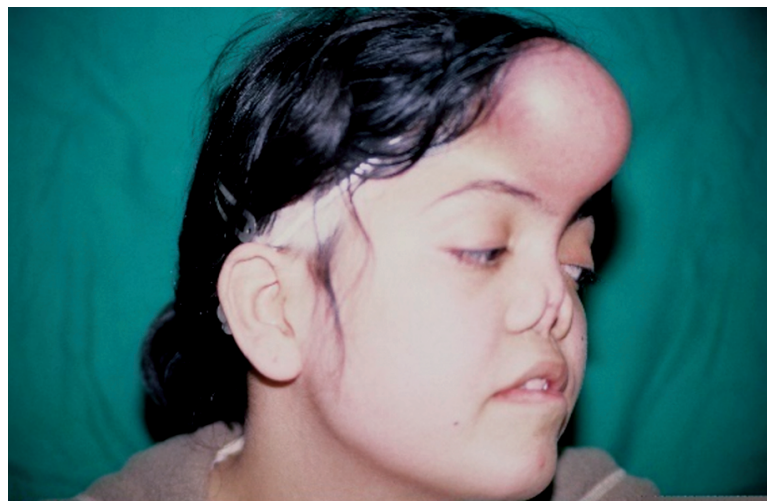

Fig. (5B): Post-operative after tissue expansion.

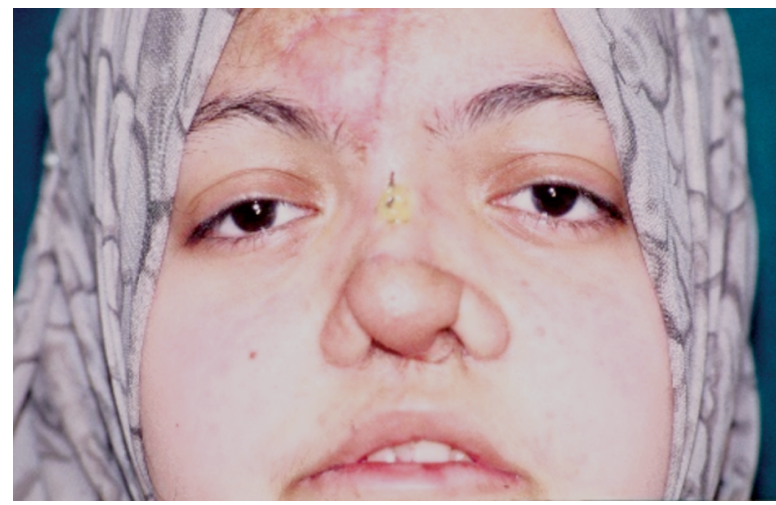

Fig. (5D): Post-operative after separation of the flap.

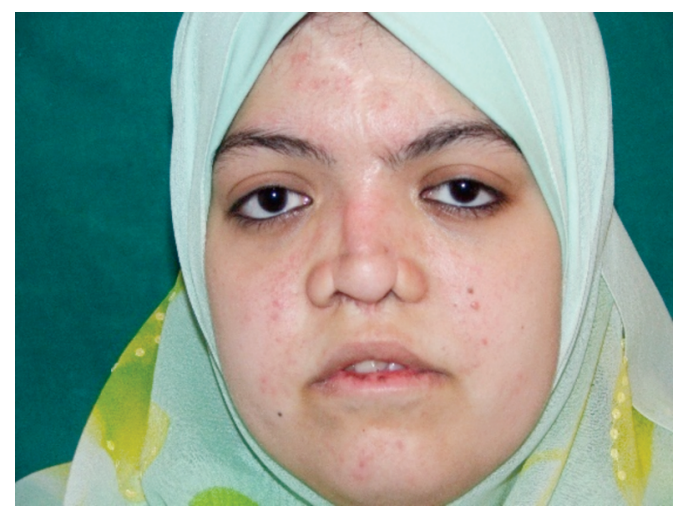

Fig. (5F): Post-operative (front view).

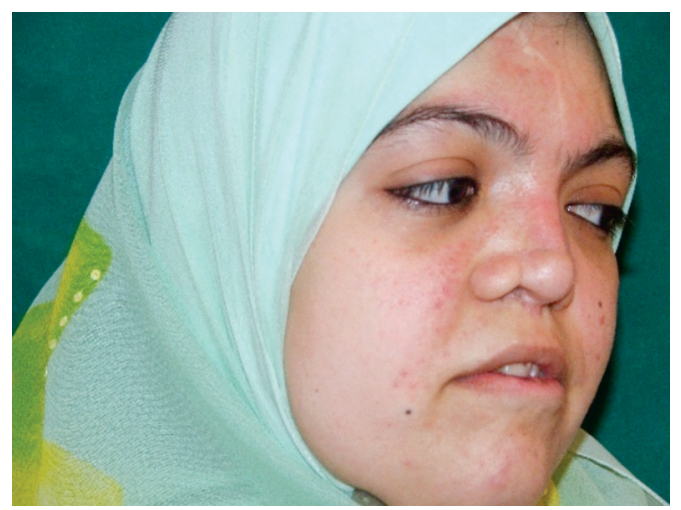

Fig. (5H): Postoperative (lateral view). 
Case 5:

Male patient 18 years old complaining of old post-burn contracted nose.

Involved subunits: Tip, columella, distal part of nasal dorsum.

\section{Procedure:}

1- Expander in the forehead $50 \mathrm{ml}$ (mentioned before), and extruded.

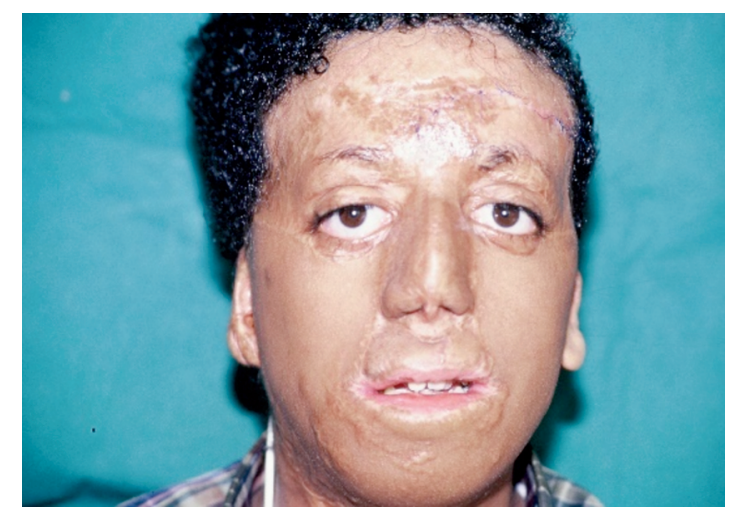

Fig. (6A): Pre-operative.

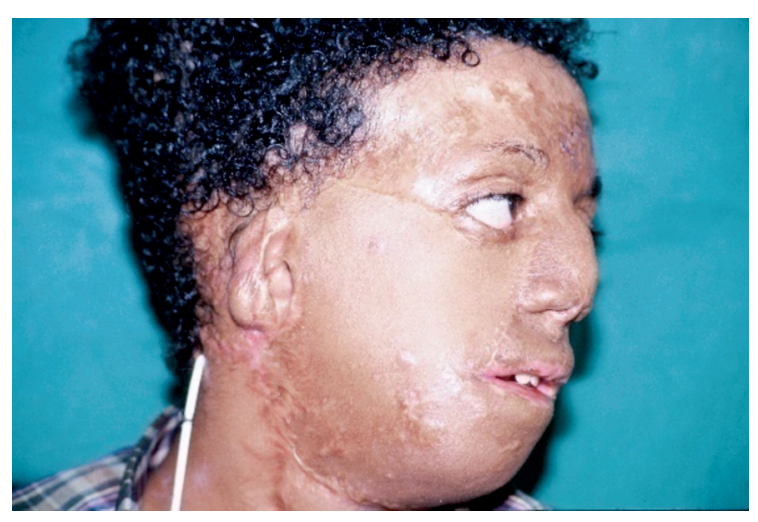

Fig. (6C): Pre-operative.

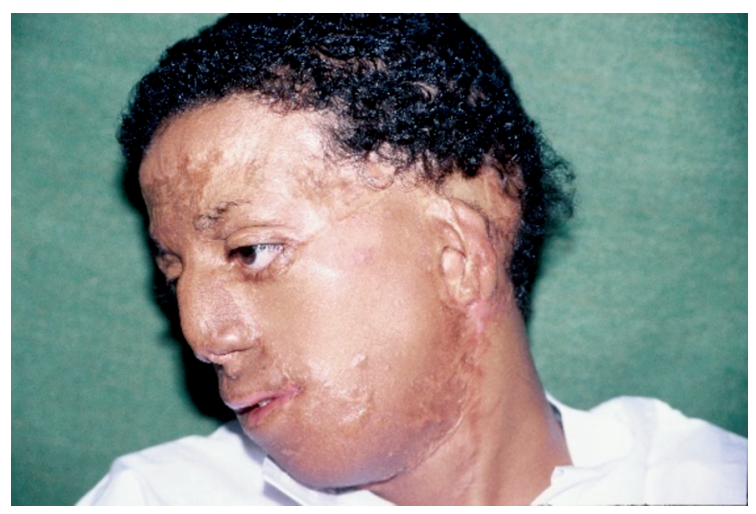

Fig. (6E): Pre-operative.
2- Excision of contracted scar and split thickness graft.

\section{Structural support:}

- Septal graft:

a- Tip graft.

b- Columellar strut.

External covering: Expanded forehead flap.

Patient satisfaction: Excellent.

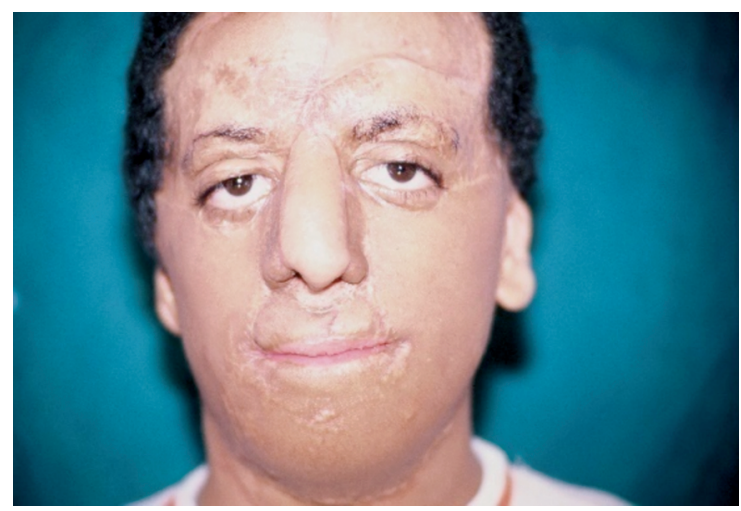

Fig. (6B): Post-operative.

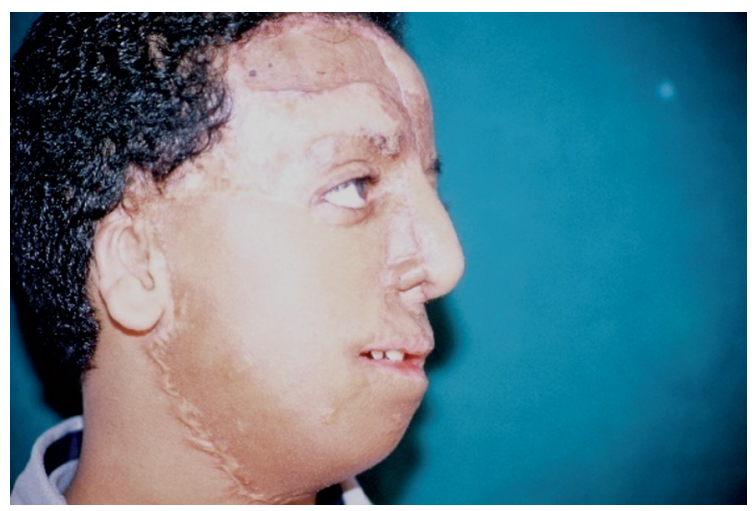

Fig. (6D): Post-operative.

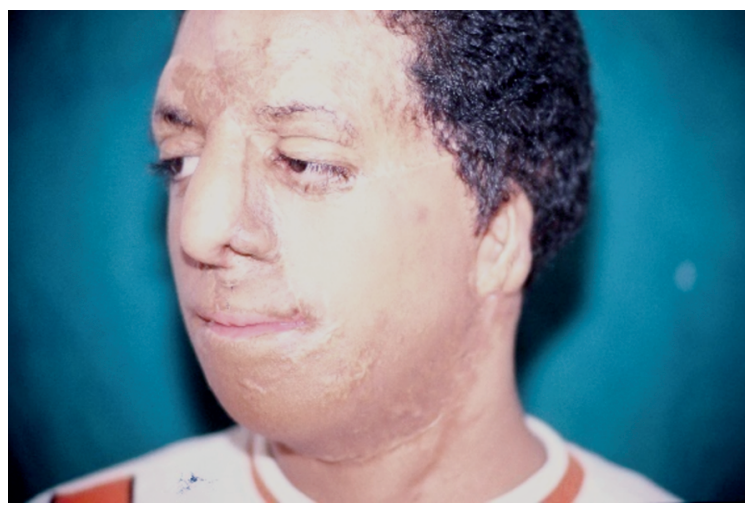

Fig. (6F): Post-operative. 


\section{DISCUSSION}

The nose is of great significance as it is the most prominent feature on the human face, critically involved in appearance, both to one self and to others, and it is involved in the perception of beauty both publicly and privately.

Because of its central location on the face, plane of projection, and relatively weak chondrocutaneous support structure, the nose is susceptible to injury, and deformities are readily apparent.

Nasal reconstruction is a state of art which started long time ago. The first mention of the treatment of nasal injuries is dated circa $3000 \mathrm{BC}$, in the Edwin smith surgical papyrus [19].

However, the breakthrough in nasal reconstruction was in 1985 after Burget and Menick emphasizing the role of subunit principle in Nasal Reconstruction [3]. Why expanded forehead flap is the best choice for nasal reconstruction:

- The tint of forehead skin.

- Well vascularized and lying adjacent to the nose [15].

- Forehead is a multilaminar structure, FTSG may be used for inner lining.

- Because of its high vascularity all types of structural support can be used.

- Large, excess forehead skin.

- Primary closure of the donor site.

- During the process of expansion, the skin is thinned out so do not need defattening.

- Recontracture do not occur.

In conclusion, what have been said by Burget and Menick about aesthetic subunits of the nose has to be respected always in any case of nasal reconstruction.

There are 10 principles that has to be always put in mind before approaching any case of nasal reconstruction. These principles are:

1- There is an inherent desire in human beings to look normal and not peculiar, horrible, or even different.

2- Our eyes see the unexpected and disregard what is or simulates normal.

3- The normal is recreated by establishment of facial contours, high lights, and land marks. The number or presence of scars is of lesser importance.

4- Flaps are designed to replace topographic units, not defects. Such designs are taken from con- tour configurations found on every human nose in an attempt to lend camouflage to the final result.

5- Exact patterns are used to design flaps.

6- The contralateral normal was used as a guide when possible.

7- Scars are always placed in wrinkle lines or along contour lines.

8- Like tissue are replaced with like tissue in three dimensions.

9- Pedicles are excised and donor sites chosen and treated aesthetically.

10- Expanded forehead flap is always a good reconstructive option in large nasal defects.

\section{REFERENCES}

1- Burget G.C. and Menick F.J.: Nasal support and lining: The marriage of beauty and blood supply. Plast. Reconstr. Srug 81: 189, 1989.

2- Millard D.R., Jr.: Aesthetic reconstructive rhinoplasty. Clin. Plast. Surg., 8: 169, 1981.

3- Burget G.C. and Menick F.G.: The subunit principle in nasal reconstruction. Plast. Reconstr. Surg., 76: 239, 1985.

4- Elliot R.: Rotation flaps of the nose. Plast. Reconstr. Surg., 44; 147: 1969.

5- Mc Gregor J.C. and Soutar D.S.: A critical assessment of the bilobed flap. BRJ Plast. Surg., 34; 197: 1981.

6- Marchac D. and Toth B.: The axial frontonasal flap revisited. Plast. Reconstr. Surg., 76: 686, 1985.

7- Herbert D.C.: A subecutaneons pedicle cheek flap for reconstruction of ala defects. BRJ Plast. Surg., 31; 79: 1978.

8- Menick F.G.: The aesthetic use of the forehead for nasal reconstruction the paramedian forehead flaps. In: Tobin $\mathrm{G}$, ed. Clinics in Plastic surgery. Hiladelphia WB Saurders, $670,1990$.

9- Menick F.J.: A 10-year experience in nasal reconstruction with the three-stage forehead flap. Plast. Reconstr. Surg., 109: 1839, 2002

10- Siegert R., Weerda H., Hoffmann S. and Mohadjer C.: Clinical and experimental evaluation of intermittent intraoperative short term. Expansion. Europ. Arch. Otorhino-laryngol., 249; 119, 1992.

11- McDowell F.: The Source Book of Plastic Surgery. Baltimore:Waverly Press, 1977.

12- Gillies H.D. and Millard R.: The principles and Art of Plastic surgery. Boston: Little, Bran, 1957.

13- Sam Naficy: Structural support. In shan R. Baker, Sam Naficy, Principles of Nasal Reconstruction. St. Louis, Mosby, 2002.

14- Weerda H.: Reconstructive Facial Plastic Surgery, Stuttgart, Geiorg. Theime Verlag, 2003.

15- Menick F.J.: Nasal Reconstruction: Forehead flap. Plast. Reconstr. Surg., 113: 100, 2004. 
16- Burget G.C.: Aesthetic restoration of the nose. Clin. Plast. Surg., 12: 463, 1985.

17- Menick F.G.: The aesthetic use of the forehead for nasal reconstruction the paramedian forehead flaps. In: Tobin G., ed. Clinics in Plastic surgery. Hiladelphia WB Saurders, 670, 1990.
18- Burget G.C. and Menick F.J.: Nasal reconstruction: Seeking a fourth dimension. Plast. Reconstr. Surg., 78: 145, 1986.

19- Breasted J.H.: Edwin Smith Surgical Papyrus. In Facsimile and Hieroglyphic Transliteration with Translation and Commentary. Chicago: University of Chicago Press, 1930. 